\title{
Meiose em Tripsacum australe Cutler e Anderson (T. dactyloides subsp. hispidum Hitchcock)
}

\author{
E. A. Graner e G. Addison \\ Escola Superior de Agricultura \\ "Luiz de Queiroz", Universidade \\ de São Paulo
}

INDICE
1) Introdução
213
215
2) Métodos
3) Meiose
215
4) Resumo e Conclusōes
217
Abstract
Literatura citada
Explicação das figuras
218
219
220

\section{1) INTRODUÇAO}

O gênero Tripsacum tem merecido ultimamente especial atenção daqueles que se dedicam aos estudos dos problemas reierentes à origem do milho, pois é considerado como um dos gêneros que contribuiram para o estabelecimento da espécie de milho hoje em cultivo e cuja forma selvagem está agora desaparecida.

A origem do milho é um problema dos mais complexos e 1oi objeto de estudos de vários investigadores. Mais recente- 
mente, vem sendo êste assunto encarado sob o ponto de vista da moderna citogenética $(1,2,10,11$ e 12) e não é nossa intencão passar aquí em revista todos êsses problemas, que poderão melhor ser analisados nas publicações originais.

CUTLER e ANDERSON (3) apresentaram ultimamente uma revisão detalhada de 7 espécies de Tripsacum e entre estas destaca-se a nova espécie por êles descrita, Tripsacum australe, até agora considerada como subespécie de $\mathbf{T}$. dactyloides. Esta espécie é, segundo os referidos autores, nativa da América do Sul, tendo sido constatada na Bolivia, Brasil, Guiana Inglêsa, Colômbia, Equador e Venezuela. Um dos autores mencionados (CUTLER), quando em Piracicaba, deixou em nossos laboratórios alguns exemplares dessa nova espécie e êste marerial serviu para várias tentativas de cruzamentos com milho e também para uma análise da meiose, que será dada a seguir.

Segundo MANGELSDORF e REEVES (10) os knobs $\left({ }^{*}\right)$ encontrados em milho teriam vindo das espécies de Tripsacum. Estudos realizados por LONGLEY (5) mostraram que espécies de Tripsacum tem "knobs" terminais e êste autor constatou em T. floridanum 22 "knobs", dos quais 21 são terminais. Um estudo detalhado dos cromosômios e da questão dos "knobs" em milho e teosinte foi também realizado por êsse autor (4, $5,6,7,8$ e 9 ).

Interessante é agora citar aqui as observações de vários autores e inicialmente de MANGELSDORF e REEVES (10), quanto ao número de "knobs" encontrados no milho e a posição geográfica das variedades estudadas. Com exceção da espécie T. australe, todas as outras espécies sāo tidas como originárias das Américas Central ou Norte e assim as variedades de milho cultivadas nas proximidades dessas regiões teriam mais probabilidade de receber "knobs" de Tripsacum, enquanto que variedades cultivadas em lugares mais afastados deveriam apresentar poucos ou nenhum "knobs". De fato, tal situação toi encontrada e foi já analisada por MANGELSDORF e REEVES (10), MANGELSDORF e CAMERON (11) e REEVES (12). incontrou-se mesmo regiões, como aquelas próximas dos Andes, onde alguns tipos de milho se apresentam sem "knobs". Ésta região é considerada por alguns autores como o provável lugar da origem do milho, enquanto que outros, como BRIEGER ( 1 e 2), pensam ser a região de origem aquela da bacia do

(*! Knobs, engrossamento dos cromosômios que se colorem intensamente $c$ observados na fase paquitene, da meiose. 
rio Paraguai. Estudos preliminares que um dos autores dêste trabalho (Graner) realizou em algumas variedades de milho clessas regiões, mostraram que de fato essas variedades apresentam poucos "knobs". Assim, por exemplo, uma variedade recebida do Acre, só apresentou um "knob" no cromosómio 7 e os tipos Chavantes e Diamantino tinham poucos "knobs", cujo número e localização não puderam ainda ser determina(los com exatidão e número que parece não ir além de 2 ou 3. A variedade Diamantino estudada apresentou também 2 cromosômios $\mathbf{B}$.

Em linhas bem gerais é essa a situaçāo referente aos "knobs" e a sua importância nos estudos da origem do milho. 'Tendo sido descrita agora a nova espécie Tripsacum australe, encontrada em estado selvagem na América do Sul, tornou-se interessante verificar esta espécie no que se refere à presença dessa estrutura, afim de se poder depois avaliar a possivel in¿luência dela na constituição do milho cultivado.

\section{2) MétODOS}

Material de 3 clones de Tripsacum australe, que se encontram cm cultivo em nossa Secção, foi fixado em três partes de alcool absoluto para 1 parte de ácido acético e conservado na geladeira. Dois dêsses clones são absolutamente idênticos, enquanto que o terceiro apresenta uma pequena variação ná ramificação da inflorescência, no comprimento das glumas e na coloração dos estigmas. Um exame rápido da melose, em todos os 3 clones, não mostrou diferença entre êles e assim estudos mais detalhados foram realizados em um dos clones, marcado em nossa coleção por T-3. Todas as preparações foram feitas com carmin acético. As espiguetas contendo as fases próprias da meiose mediram cêrca de $8 \mathrm{~mm}$. e as anteras contendo figuras em diacinese, aproximadamente $3 \mathrm{~mm}$, apresentando-se com uma coloração parda.

\section{3) MEIOSE}

A meiose em Tripsacum australe não é difícil de ser estudada, pois, encontrando-se o tamanho apropriado da antera, is células são grandes e muitas fases da meiose se apresentam com bastante frequência.

A fase leptotene típica não foi encontrada. Em compensação, células em sinizese são muito frequentes (Fig. 5). A fase zigotene é difícil de ser analisada e a fase seguinte, paquitene, 
é encontrada com facilidade (Figs. 1, 2, 3, 4 e 6). Nesta fase os cromonemas pareados se apresentam bem engrossados e em algumas células êstes pares estăo bem separados, permitindo um estudo mais detalhado deles. Os cromosómios pequenos ficam muitas vezes isolados, permitindo um estudo de todo o seu comprimento, o mesmo nåo acontecendo com os cromosómios grandes, que ficam em parte emaranhados com os demais. 0 número de pares de cromosómios náo é possivel ser determinado nesta fase, como também não é fácil constatar-se a duplicidade de cada cromonema componente de um par e duplicidade esta que, de acórdo com o que se sabe hoje sobre o momento da divisão longitudinal, deve existir, só não sendo observada por dificuldades de técnica. Há diferença na estrutura dos cromonemas mas é interessante observar que nada que possa ser comparado a um "knob" típico parece existir. A ausência de "knobs" nesta espécie e, principalmente "knobs" terminais, como aqueles demonstrados por LONGLEY (5) para outra espécie do gênero, pode bem ser verificada no caso dos cromosómios peqenos. As figuras 1, 2, 3 e 4 mostram bem esta situação. Na fig. 1 estão assinalados por flechas dois cromosómios pequenos desta espécie, que năo apresentam "knobs". Também algumas extremidades dos grandes cromosômios podem ser examinadas, não apresentando essas estruturas. As mesmas figuras mostram ainda que provàvelmente năo existem "knobs" nas demais regioes dos cromosómios, mas esta afirmaçăo năo pode ser tomada como decisiva, pois houve multas vezes dificuldades no exame do cromosômio em tóda a sua extensão. Porém, sempre quando possivel o exame de regiðes nåo terminais dos cromosómios, năo foram nelas constatados "knobs". A fase seguinte, diplotene, pode ser examinada nas figuras $7,8,9$, e 10. A fig. 7 mostra muito bem o inicio de separaçăo dos pares de cromatídeos irmáos, indicando o início da fơrça de repulsão contrariando a fórça de atraçăo, que até sgora mantinha os pares em conjunto. Esta separação é impedida em alguns pontos, formando os quiasmas e que podem ser constatados nas figuras mencionadas. Pode-se verificar nesta fase a grande diferença de tamanho dos cromosómios e o número variável de quiasmas para cada cromosómio, que dão formas diferentes às tétrades, conforme a sua localização. $O$ engrossamento notado a partir do paquitene acentua-se cada vez mais na fase diplotene e engrossamento êste que é progressivo, mostrando a figura 10 já as têtrades bem separadas umas das outras. As figuras 11 e 12 mostram a fase diacinese, onde os pares de cromosómios estão bem distintos, notando-se 
ao mesmo tempo uma diminuição de tamanho do nucléolo. Pode-se nesta fase contar perfeitamente o número de pares de cromosômios, que é 18. Alguma diferença de tamanho pode ¿á ser observada. Com o desaparecimento do nucléolo, chegase à metáfase I, mostrada na figura 13 , onde se pode melhor. verificar a diferença de tamanho dos cromosômios. A contração deles é mais intensa e a estrutura em pares deixa também de ser visível, podendo-se contar nesta fase muito bem 18 unidades, que é o número haplóide de cromosômios desta espécie. As figuras 14 e 15 indicam estados na anáfase I. A fig. 14 mostra uma anáfase muito inicial e a fig. 15 uma anáfase bem avançada, 18 cromosômios sendo então distribuidos regularmente para cada polo. A fig. 16 mostra um fim de anáfase I e a fig. 17 uma intercinese. Segue-se também uma divisão do citoplasma e em cada uma das duas novas células formadas dá-se agora a metáfase II. A fig. 18 A mostra 2 metáfases II, onde pode-se perfeitamente contar o número de cromosômios e onde se verifica também muito melhor a diferença de tamanho entre éles. Por esta figura pudemos reunir os cromosômios em grupos, conforme o seu tamanho. Assim, distinguimos três grupos: grandes, médios e pequenos. No grupo grande encontramos dois cromosômios, no médio 6 e no pequeno 10 cromosômios, assinalados na figura pelas letras G, M, e P, respectivamente. A figura 19 mostra a telófase II e a figura 20 uma tétrade. As figuras 21 e 22 mostram diferentes estados do grão do pólen.

\section{4) RESUMO E CONCLUSÓES}

Depois de uma breve introdução, mostrando a importância que o gênero Tripsacum desempenha hoje nos problemas da origem do milho, fizemos um estudo detalhado da meiose na nova espécie Tripsacum australe, descrita recentemente por CUTLER e ANDERSON (3) e espécie esta encontrada em estado selvagem na América do Sul.

Todas as fases da meiose mostraram-se normais e o número de cromosômios, facilmente determinado nas fases diacinese, metáfase I, metáfase II, é de 18 para a fase haplóide. Esta espécie não difere, quanto ao número de cromosômios, da forma diplóide Tripsacum dactyloide e da espécie Tripsacum floridanum, estudadas por LONGLEY (5). Segundo MANGELSDORF e REEVES (10) as formas de Tripsacum encontradas na América Central têm 72 cromosômios e são consideradas como autotetraploides. 
Entretanto, no que se refere à presença de "knobs" nos cromosómios, esta espécie parece diferir da espécie estudada por LONGLEY (5). Tripsacum australe não apresenta "knobs" nas extremidades dos cromosómios e provavelmente também nas outras regióes pois as figuras que puderam ser examinaclas não mostraram essa, estrutura.

Segundo MANGELSDORF e REEVES (10) os “knobs" presentes no milho teriam vindo de Tripsacum, por meio de cruzamento entre êstes dois gêneros. Assim sendo, os tipos de milho cultivados próximos ao centro de distribuiçăo das espécies de Tripsacum até então conhecidas, e que é a região da América Central, principalmente o México, deveriam se apresentar bastante contaminados por êste gênero e apresentariam mais "knobs" do que aqueles tipos de milho cultivados jonge da referida região. Observações de vários autores $(6,7,9$, 16, 11 e 12) confirmam esta hipótese, inclusive aquelas realizacias por um dos autores dêste trabalho (Graner, não publicado) em material sul-americano.

Tendo sido encontrada agora esta nova espécie de Tripsacum ila América do Sul, aparentemente sem "knobs", torna-se interessante verificar se ela não poderia ter contribuido para o estabelecimento das formas de milho sem "knobs" encontradas na América do Sul. Cruzamentos entre milho e Tripsacum iustrale foram realizados por um dos autores (Addison), não t.endo porém produzido sementes. Outras pesuisas tornam-se então necessárias afim de que se possa tirar conclusões a respeito cie tão importante assunto.

\section{ABSTRACT}

The meiosis of Tripsacum australe, a new specie native in South America and described by CUTLER and ANDERSON (3) was studied in detail. All stages were found to be normal and the chromosome number equal to 18 in the haploid phase.

The most peculiar fact found in this plant was the absen(:e of knobs, mainly at the end of chromosomes and shown in figs. 1 to 4 . According to the above observations, this specie sfems to be different from the species studied by LONGLEY (5) and the importance of this point regarding the problems of origin of maize was emphasized. 


\section{LITERATURA CITADA}

1) BRIEGER, F. G. (1944) Origem do milho. Revista de Agricilltura. 18: 409-418.

2) BRIEGER, F. G. (1944) Estudos experimentais sôbre a origem do milho. Anais da Escola Superior de Agricultura "Luiz de Queiroz". (Em impressão).

3) CUTLER, H. C. and E. ANDERSON (1941) A preliminary Survey of the Genus Tripsacum. Annals of Missouri Botanical Garden. 28: 249-269.

4) LONGLEY A. E. (1924) Chromosomes in Maize and Maize Relatives. Journal of Agricultural Research. 28: 673-681.

5) LONGLEY, A. E. (1937) Morphological Characters of Teosinte Chromosomes. Journal of Agricultural Research. 54: 835-862.

6) LONGLEY, A. E. (1938) Chromosome of Maize from North American Indians. Journal of Agricultural Research. 56: 177-195.

7) LONGLEY, A. E. (1939) Knob position on corn chromosomes. Journal of Agricultural Research. 59: 475-490.

8) LONGLEY, A. E. (1941) Knob positions on teosinte chromosomes. Journal of Agricultural Research. 62: 401-413.

9) LONGLEY, A. E. (1941) Chromosome morphology in maize and its relatives. Botanical Review. 7: 263-289.

10) MANGELSDORF, P. C. and R. G. REEVES (1939) The origin of indian corn and its relatives. Texas Agricultural Experiment Station. Bulletin N. 574.

11) MANGELSDORF, P. C. and J. W. CAMERON (1942) Western Guatemala, a secondary center of origin of cultivate maize varieties. Botanical Museum Leaflets, Harvard University. 10: 217-252.

12) REEVES, R. G. (1944) Chromosome knobs in relation to the origin of maize. Genetics. 29: 141-147. 


\section{EXPLICACAO DAS FIGURAS}

Figs. 1 a 4 - Paquitene. Notar a ausência de knobs nas extremidades, assinaladas por setas nas figs. 2 e 4. A figura 1 mostra, assinalados por setas, dois cromosómios pequenos, t.3mberm sem knobs. $(X 1000)$.

Fig. 5

Fig. 6

Fig. 7, 8, 9 e 10

Fig. 11 e 12

Fig. 13

Fig. 14 e 15

Fig. 16

Fig. 17

Fig. 18

Fig. $18 \mathrm{~A}$

Fig. 19

Fig. 20

Fig. 21 e 22
Sinizese

Paquitene

Diplotene

Diacinese

Metáfase I

Anáfase I

Fim da Anáfase I

Intercinese

Anáfase II e Metáfase II

Metáfase II

Telófase II

Tétrade

Grãos de pólen
( $\times$ 500)

$(\times 500)$

( $\times$ 500)

$(\times 500)$

( $\times$ 500)

$(\times 500)$

$(\times 500)$

$(\times 500)$

( $\times 500)$

( $\times$ 2000)

$(\times 500)$

$(\times 500)$

$(\times 500)$ 


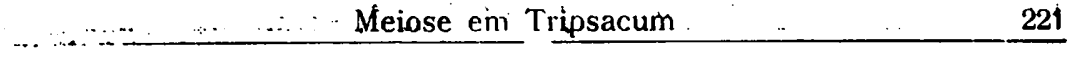

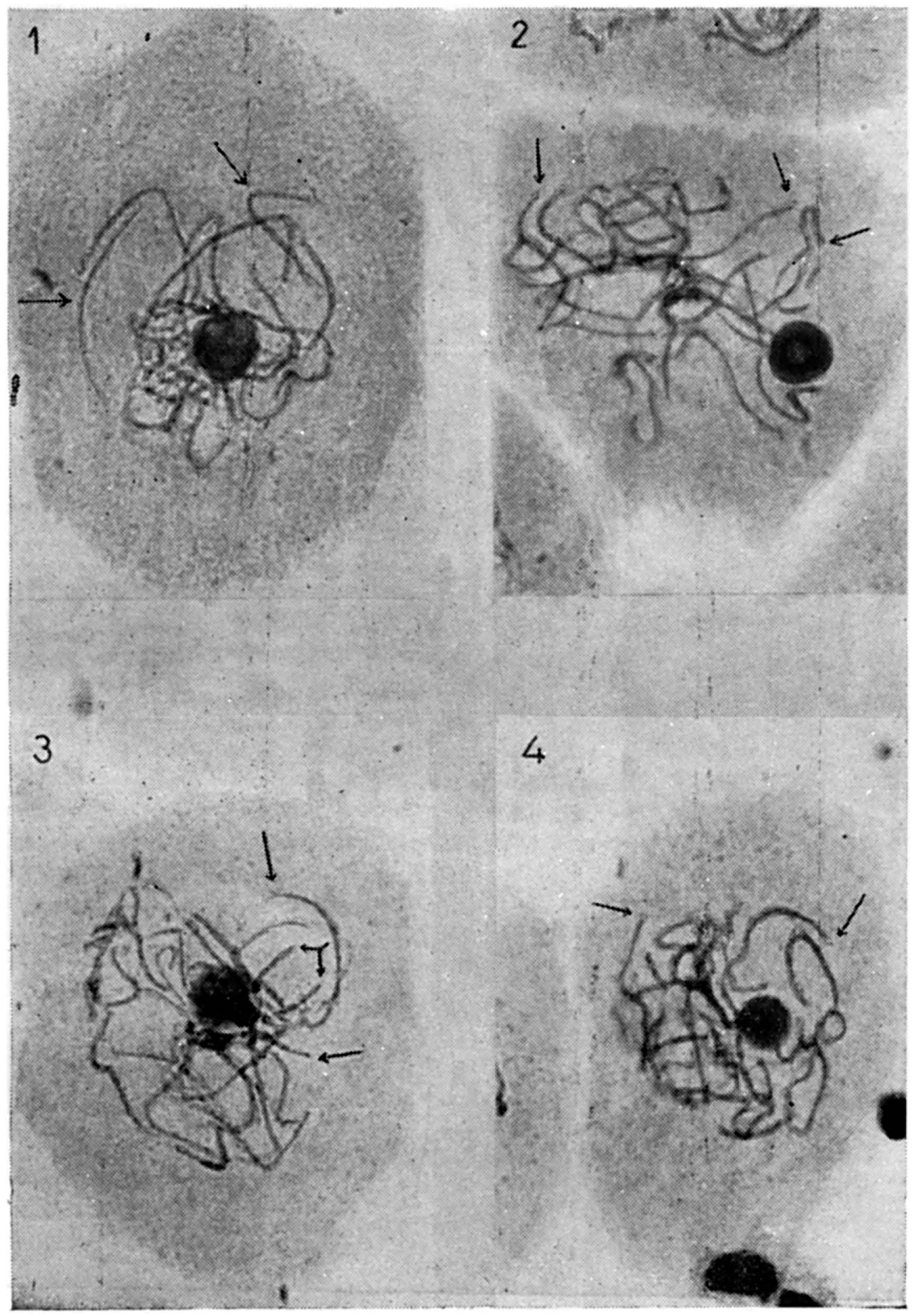




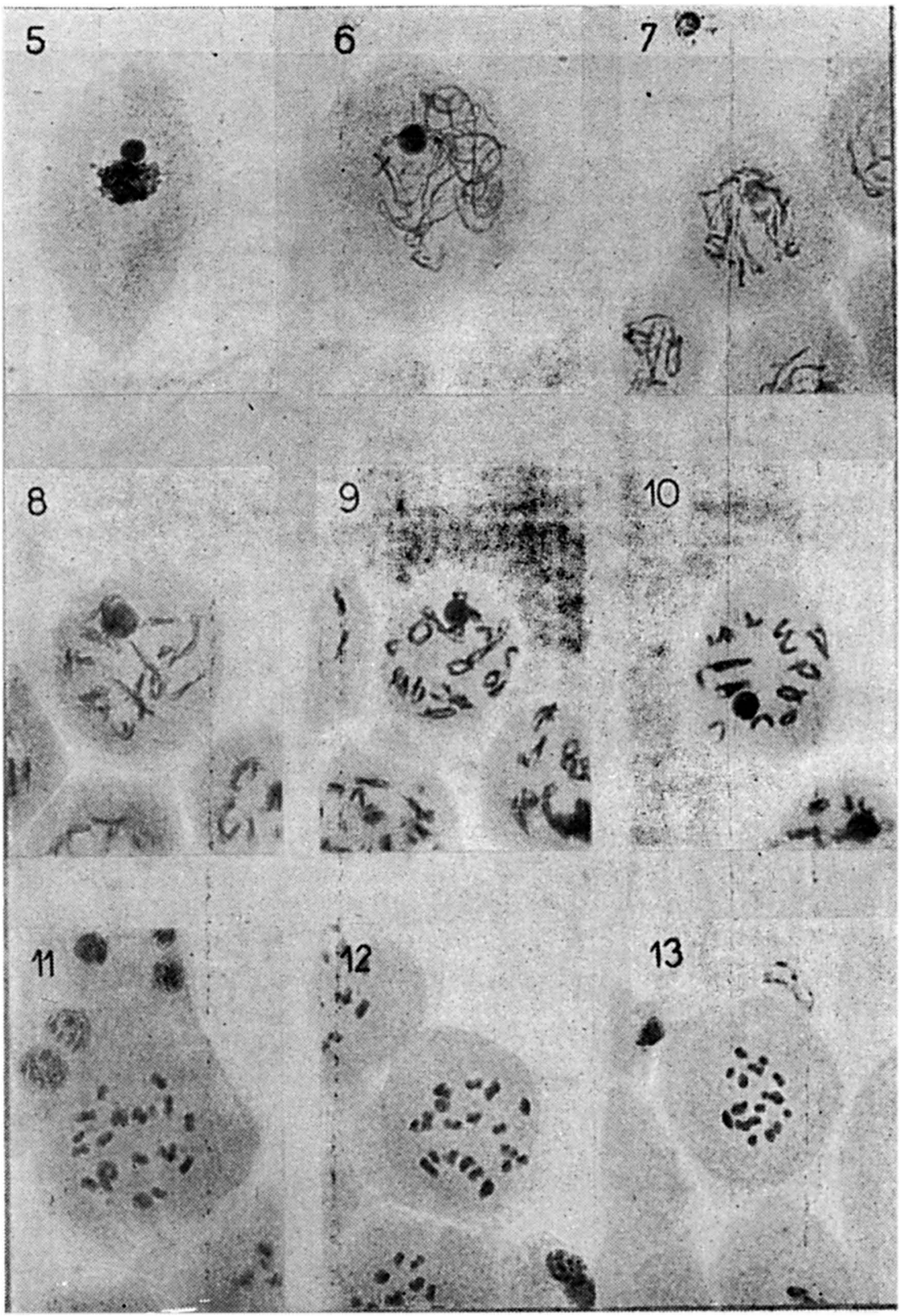




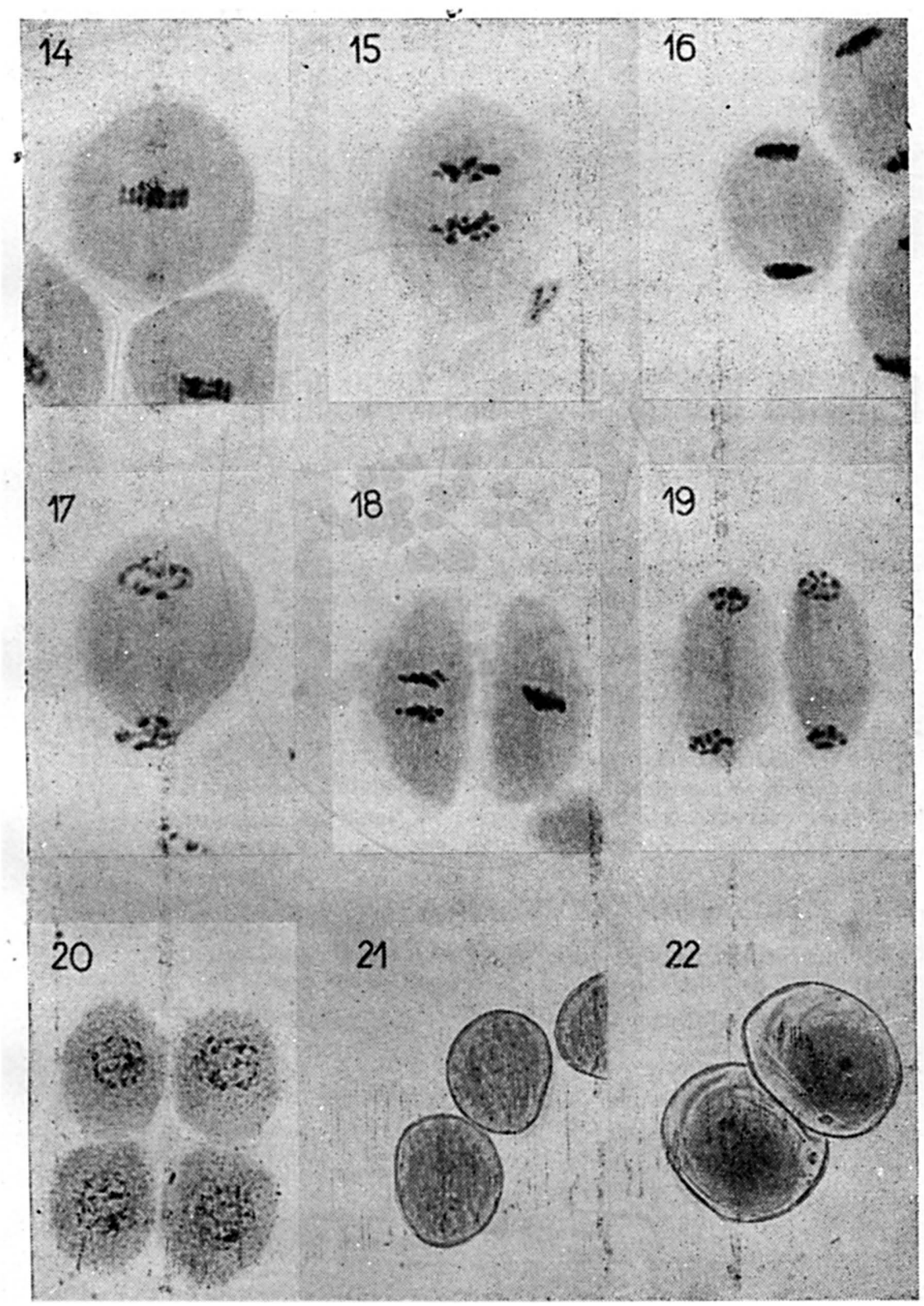




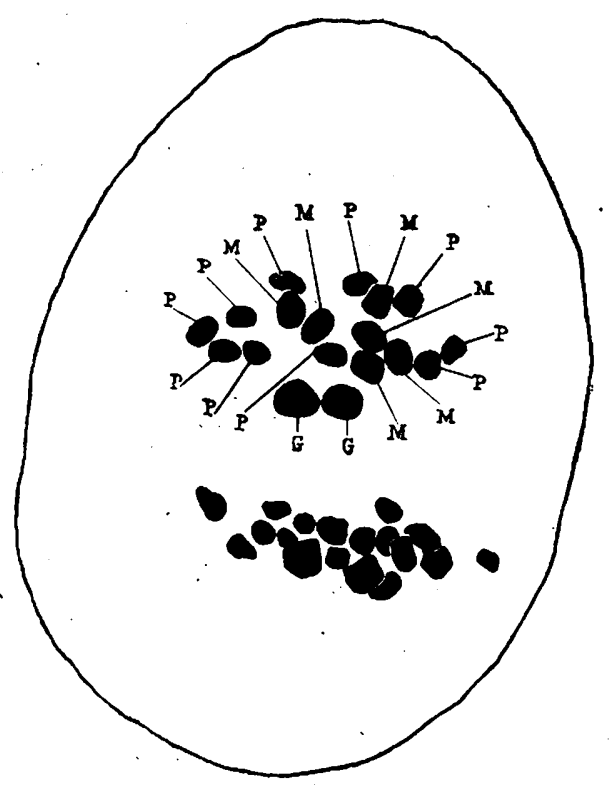

$18 \mathrm{~A}$ 